\title{
Enzyme catalysis with small ionic liquid quantities
}

\author{
Fabian Fischer $\cdot$ Julien Mutschler $\cdot$ Daniel Zufferey
}

Received: 4 October 2010/Accepted: 9 November 2010/Published online: 24 November 2010

(C) Society for Industrial Microbiology 2010

\begin{abstract}
Enzyme catalysis with minimal ionic liquid quantities improves reaction rates, stereoselectivity and enables solvent-free processing. In particular the widely used lipases combine well with many ionic liquids. Demonstrated applications are racemate separation, esterification and glycerolysis. Minimal solvent processing is also an alternative to sluggish solvent-free catalysis. The method allows simplified down-stream processing, as only traces of ionic liquids have to be removed.
\end{abstract}

Keywords Enzyme catalysis · Solvent free · Ionic liquid · Multiphase $\cdot$ Coating

\section{Introduction}

Ionic liquid coated enzymes are catalysts for multiphase minimal solvent processing. Since the beginning of their use as green solvents for chemical synthesis, ionic liquids have been considered to enhance sustainability and reduce process cost [28]. They are considered widely for use in enzymatic catalysis, but no large-scale industrial biotransformation that exploits them has so far been established. The rational use of ionic liquids is a current research

F. Fischer $(\bowtie) \cdot$ J. Mutschler

Institute of Life Technologies, University of Applied Sciences

Western Switzerland, HES-SO Valais, Route du Rawyl 64,

1950 Sion 2, Switzerland

e-mail: fabian.fischer@hevs.ch

D. Zufferey

Institute Systems Engineering, University of Applied Sciences Western Switzerland, HES-SO Valais, Route du Rawyl 47, 1950 Sion 2, Switzerland activity that also implies investigations on physical properties and biocompatibility.

The relative facility of the synthesis of ionic liquids results in an ever-increasing amount of ionic liquid variants for which prices tend to be lower on a high level. Therefore conceptual approaches are sought to develop low price bioconversions (Fig. 1). This report aims to provide insight into the use of small amounts of ionic liquids for the development of sustainable biotransformations. The use of small solvent quantities is an important step forward in the development of cost-effective green processing.

\section{Activation of enzymes through ionic liquids}

Enzymes are isolated catalytic proteins for the use in foreign but specifically defined and controlled environments. For their optimal use parameters like $\mathrm{pH}$, water activity, and temperature need to be chosen carefully. When biocatalysts are used in non-aqueous environments such principal parameters are difficult to control in a proper manner. Ionic liquids are considered as a tool for allowing more control because they provide polarities close to those of water and many of them seem to be compatible with enzymes. The interactions of ionic liquids with enzymes on a molecular level are not well understood and represent an active research field. In any case, ionic liquids can be applied as anhydrous solvents even if their precise influence on enzyme activity cannot be predicted. This is in contrast to purely aqueous conditions, where combinations with water-miscible ionic liquids follow the Hofmeister series [32].

Enzymes are catalysts of fragile nature. To stabilize them for industrial biotransformation they are usually immobilized on polymer matrixes or mixed with stabilizing 


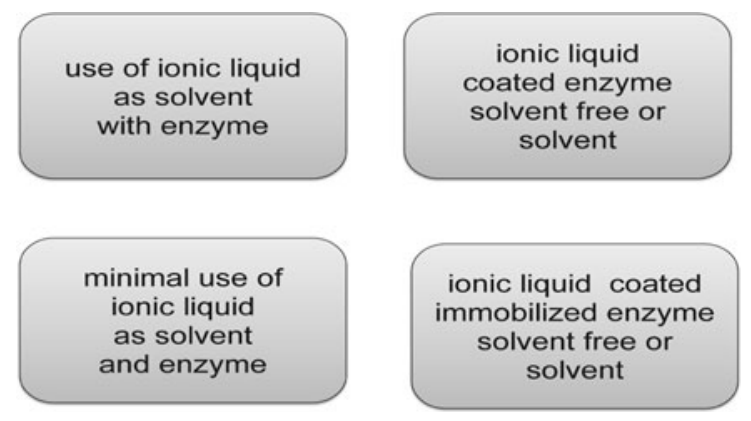

Fig. 1 Four methods of using ionic liquid in enzyme catalysis that comprise homogeneous and heterogeneous processing

compounds. The immobilisation is also helpful for downstream processing and recycling. It was discovered that ionic liquids also immobilize and stabilize Candida antarctica lipase B [18]. In esterifications lipase showed superior activity in [emim] $\left[\mathrm{BF}_{4}\right]$, [emim] $\left[\left(\mathrm{CF}_{3} \mathrm{SO}_{2}\right)_{2} \mathrm{~N}\right]$, $[\mathrm{bmim}]\left[\mathrm{PF}_{6}\right]$ and $[\mathrm{bmim}]\left[\left(\mathrm{CF}_{3} \mathrm{SO}_{2}\right)_{2} \mathrm{~N}\right]$, whereas hexane and 1-butanol reduced productivity. These activities were observed with ionic liquids used in solvent quantities. As ionic liquids are expensive, the question is how much of an ionic liquid is needed for enzyme catalysis?

Ionic liquids are able to deactivate enzymes, which is unfortunately the usual case, according to our experience. The activation of enzymes through ionic liquids is therefore a challenging and stimulating subject, and many successful combinations have been found [21, 33]. Enzyme activity in ionic liquids depends to an important extent on available water quantities to maintain hydrogen bonds that ensure correct three-dimensional protein structure, which is a prerequisite for catalytic activity. Therefore an ionic liquid should not be strongly hygroscopic in minimal water conditions to prevent enzyme dehydration. Another cause for reduced activity is impurities, which are occasionally found in ionic liquids. They can reduce enzyme activity in an unpredictable manner and need to be controlled [31]. A further parameter is the polarity of the ionic liquid because it appears to be an important factor in enzyme activity. The polarity of common ionic liquids ranges from $E_{T}^{N}=0.35$ up to 1 on the Reichardt polarity scale [27]. At the lower end $\left(E_{T}^{N}=0.35\right)$ they correspond to the often successfully used acetone in lipase-mediated esterifications and on the upper side to pure water $\left(E_{T}^{N}=1\right)$. Therefore it is suggested that ionic liquids are compatible with enzymes as they resemble water in terms of polarity. It was found that more polar ionic liquids improved yields, whereas very polar organic solvents deactivate enzymes [24]. The observed activation and deactivation of enzymes can also be regarded as a solubility-based phenomenon of substrates that are incompatible or compatible with the ionic liquids used. As mentioned earlier, enzymes can be dehydrated, in particular in polar solvents, and consequently lose their function. On the other hand some ionic liquids are polar but water repellent, which is a rather exceptional property not known for other solvents. These contrasting properties are found in particular with fluorinated anions such as $\mathrm{PF}_{6}{ }^{-}$or $\left(\mathrm{CF}_{3} \mathrm{SO}_{2}\right)_{2} \mathrm{~N}^{-}$, which resemble perfluorinated solvents, like $\mathrm{CF}_{3}\left(\mathrm{CF}_{2}\right)_{4} \mathrm{CF}_{3}$, that are water repellent and non-polar. The water-repellent ionic liquids also comprise cationic long alkyl chains but they are usually not very polar. The advantage of water-repellent ionic liquids in terms of enzyme activity is the fact that they not dehydrate enzymes and therefore structure and function are maintained. On the other hand ionic liquids that do not mix easily with water often do not mix well with biomolecules.

The present report is mostly about ionic liquids used as a coating of immobilized enzymes. The use of ionic liquid as a film coating is actually a use of minimal amounts of ionic liquids in multiphase processing.

\section{Ionic liquid enzyme coating as minimal solvent use}

Minimal solvent use is simply the use of an optimal solvent quantity for a given transformation. Ionic liquid coated enzymes improve stereoselectivity and accelerate otherwise unproductive transformations. The use of ionic liquid coated enzymes is still an emerging subject and not that many examples are found in the literature. Two types of coating are described: the coating of pure enzymes with ionic liquids and the coating of immobilized enzymes. The following sections give an overview of literature concerning these two kinds of coatings as well as for a third option, the optimized quantity of ionic liquids that comes close to the concept of ionic liquid coating.

Ionic liquid coating improves racemate resolution

The resolution of racemates is an obvious use for enzymes in industrial biotransformations usually employing lipases [15]. Enzymes are enantioselective catalysts and therefore the best solution to separate racemates. It is therefore just a small step to use ionic liquids in combination with enzymes for the purification of racemic mixtures.

Ionic liquid coated enzymes have been studied in combination with organic solvents [14]. As ionic liquid 1-(3'-phenylpropyl)-3-methylimidazolium hexafluorophosphate $[\mathrm{ppmim}]\left[\mathrm{PF}_{6}\right]$ was employed (Scheme 1). This ionic liquid melts above $53^{\circ} \mathrm{C}$ and the coating was realized by mixing melted [ppmim] $\left[\mathrm{PF}_{6}\right]$ with the lipase from Pseudomonas cepacia and then cooling the mixture to room temperature. Enhanced enantioselectivity by conservation of the activity was found. In fact the enantioselectivity improved by a factor two or remained comparable to purely 
Scheme 1 Racemate resolution by stereoselective lipase in irreversible esterification with vinyl acetate<smiles>[R]C(O)[C@@H](C)OC(C)=O</smiles>

principally used ionic liquids:

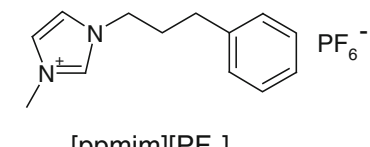<smiles>CCCCn1cc[n+](C)c1C</smiles>

$[\mathrm{ppmim}]\left[\mathrm{PF}_{6}\right]$

$[\mathrm{bdmim}]\left[\mathrm{BF}_{4}\right]$

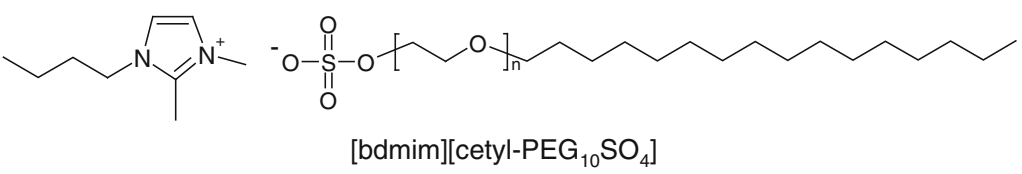

organic solvent conditions. The catalyst appeared to be robust and multiple reuses of it were possible. The simplicity of preparation and the superior properties of the catalyst are a promising concept and this invention was patented [11].

The resolution concept was applied successfully by other researchers. Certain ionic liquids even provide much higher reaction rates, while improving enantioselectivity [9]. In particular imidazolium salts derived from polyoxyethylene cetyl sulfate (PS) used in combination with hexane or diisopropyl ether improved lipase-mediated transesterifications of 1-phenylethanol with vinyl acetate (Scheme 1). The ionic liquid coating of lipase PS with $i$ - $\operatorname{Pr}_{2} \mathrm{O}$ as solvent improved the reaction rate by a factor 1,000 for certain substrates. A similar effect was observed for ionic liquid coated Candida rugosa lipase [10]. The principal role of ionic liquids in racemate separations is to improve stereoselectivity. Ionic liquids are also used to enable esterifications that would otherwise be unproductive.
Coated immobilized lipase in irreversible esterification

Ionic liquid coated immobilized Candida antarctica lipase B (Novozyme 435) improved the irreversible transesterification of citronellol by up to twofold with a range of fatty acid vinyl esters (Scheme 2). The substrate conversions were quantitative and over $99 \%$ product was isolated. These conversions were realized in solvent-free conditions at $70^{\circ} \mathrm{C}$ [19], where the liquid substrates serve as solvent. The high conversion rates are also a result of the use of vinyl esters that lead to irreversible reactions because the leaving enol $\left(\mathrm{CH}_{2}=\mathrm{CHOH}\right)$ tautomerizes into "unreactive" acetaldehyde $\left(\mathrm{CH}_{3} \mathrm{CHO}\right)$ (Scheme 2$)$. An homologous series of imidazole-based hexafluorophosphates, such as [bmim $]\left[\mathrm{PF}_{6}\right],[\mathrm{hmim}]\left[\mathrm{PF}_{6}\right]$ and $[\mathrm{omim}]\left[\mathrm{PF}_{6}\right]$, were employed as the ionic liquid coating.

A triphasic process variant with ionic liquid coated immobilized lipases is possible through the use of supercritical carbon dioxide $\left(\mathrm{scCO}_{2}\right)$ as solvent (Fig. 2). After the process the $\mathrm{scCO}_{2}$ is easily removed from reaction
Scheme 2 Transesterification of citronellol with fatty acid vinyl esters catalysed by ionic liquid coated Novozyme 435 (NZ435)

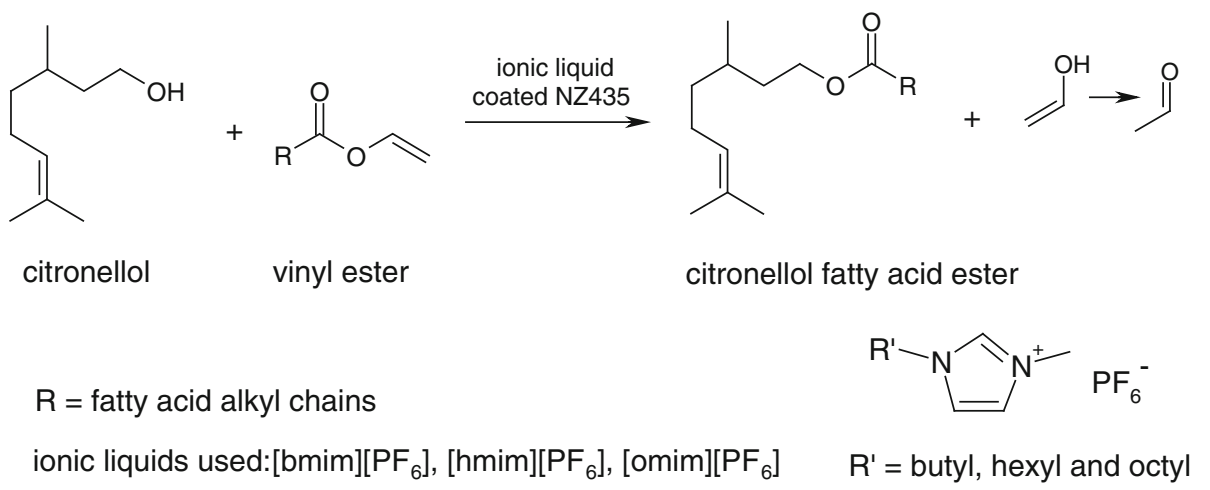




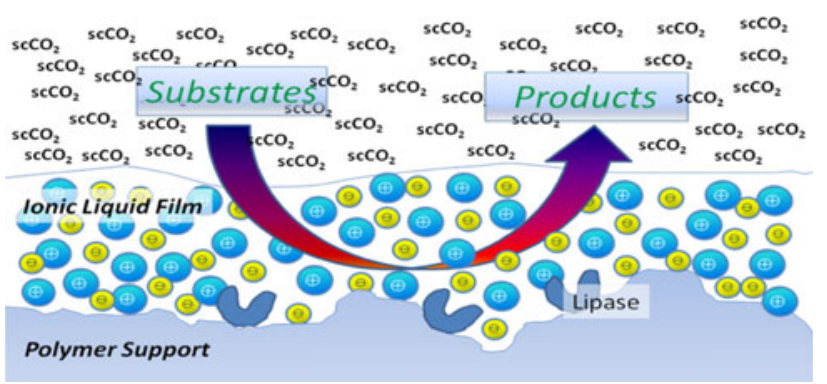

Fig. 2 Triphasic conversion with ionic liquid coated immobilized lipase in $\mathrm{scCO}_{2}$

mixtures by evaporation and recovered for repeated use $[6,20]$.

Reversible esterification with coated immobilized lipase

Ionic liquid coated macroporous polyacrylate lipase carriers (Novozyme 435) offer feasible solvent-free biotransformation of surfactants. Conversions of up to $80 \%$ by butylmethylpyridinium hexaflurophosphate, $\left[4 \mathrm{mbpy}^{2}\left[\mathrm{PF}_{6}\right]\right.$, match closely the capacity of the best organic solvents. This was shown in a solvent polarity trend study with myristic acid [22]. The ionic liquid coating leads to a pseudo-solvent-free reaction [2]. The technique can also be considered as a minimal solvent use application with green solvents. In any case the minimal use of ionic liquids in comparison to bulk quantities is a way to save on often expensive ionic liquids. Moreover, the small amounts of ionic liquids in use allow a simple workup that contrasts with transformations where ionic liquids are employed in solvent quantities. The esterification of $\alpha$-methylglucoside with the fatty acids mediated by ionic liquid coated Novozyme 435 was $\sim 4.5$ times more efficient than solvent-free transformations (Scheme 3). The $\mathrm{C}_{10}$ and $\mathrm{C}_{18: 1}$ fatty acids were also converted, which was not the case with untreated Novozyme 435 under solvent-free conditions [22]. The most interesting observation was that the higher the polarity of the ionic liquid used as coating, the more productive the transformations (Fig. 6). The opposite trend is obtained by the use of the same ionic liquids as solvent, where higher polarity yielded lower product quantities (Fig. 4). The best conversion was realized when butylmethylpyridinium hexaflurophosphate [4bmpy] $\left[\mathrm{PF}_{6}\right]$, with a polarity of $\left(E_{T}^{N}=0.88\right)$ on the Reichardt's scale, was used. In this case, an $80 \%$ conversion was obtained which is in sharp contrast to the $18 \%$ obtained with the same ionic liquid in solvent quantities. The reason for the more satisfying results in the former case is possibly related to the fact these ionic liquids provide a better interaction with at least one of the substrates, here with $\alpha$-methylglucoside. The second substrate, myristic acid, is liquid at $60^{\circ} \mathrm{C}$ and does not need to be dissolved by the ionic liquid if it can access the active site in the enzyme. This is in fact possible as the total mass of ionic liquid in use is below $20 \%$ of the total reaction mixture and therefore not a dominating factor in the mixing process. This
Scheme 3 Regioselective O-6 acylation on $\alpha$-methylglucoside with fatty acids (capric, lauric, myristic, palmitic, and oleic) by ionic liquid coated immobilized lipase
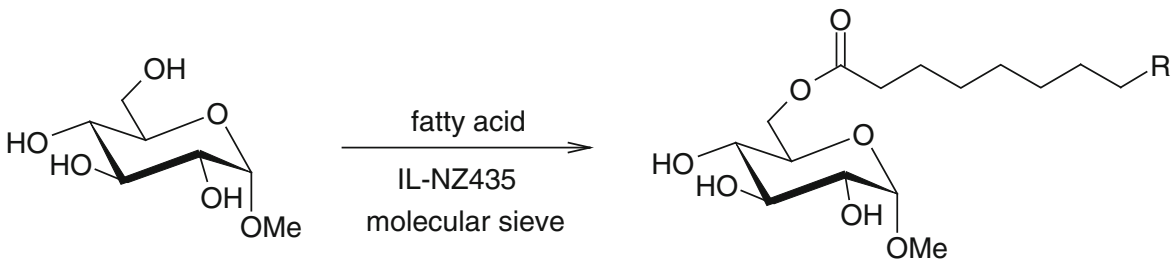

$$
\mathrm{R}=-\mathrm{CH}_{2} \mathrm{CH}_{3},-\left(\mathrm{CH}_{2}\right)_{3} \mathrm{CH}_{3},-\left(\mathrm{CH}_{2}\right)_{5} \mathrm{CH}_{3},-\left(\mathrm{CH}_{2}\right)_{7} \mathrm{CH}_{3},-\mathrm{CH}=\mathrm{CH}\left(\mathrm{CH}_{2}\right)_{7} \mathrm{CH}_{3}
$$

used ionic liquids:

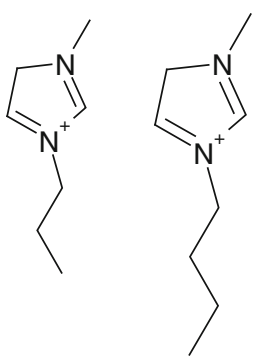

anions $=\mathrm{PF}_{6}^{-}$or $\mathrm{BF}_{4}^{-}$

pmim bmim

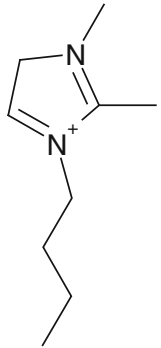

bdmim<smiles>CCCC[n+]1ccc(C)cc1</smiles>

4mbpy

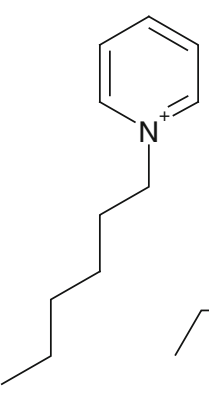

hpyr 
Substrate-Product Phase

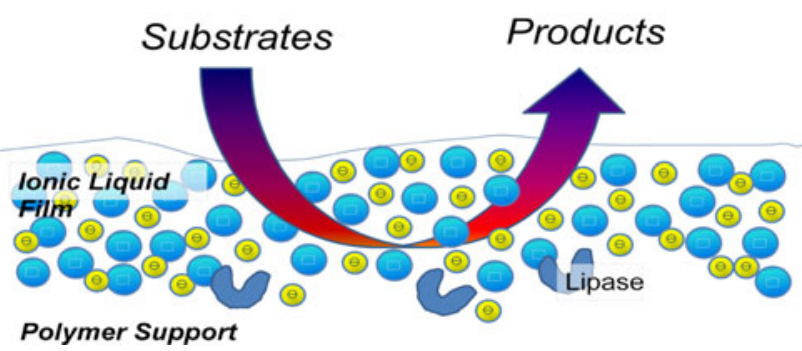

Fig. 3 Multiphase use of ionic liquid coated immobilized lipase. The ionic liquid coating is a film that covers the surface of the polymeric matrix on which the lipase is immobilized

transformation is a good candidate for multiphase enzyme catalysis under quasi-solvent-free conditions (Fig. 3).

Glycerolysis of fats and oils with minimal ionic liquid quantities

Glycerolysis of oils and fats from sunflower, rape seeds and fish was examined in small to optimized quantities of ionic liquids (Scheme 4). The amphiphilic cocosalkyl pentaethoxymethyl ammonium methoxysulfate, [cpma][ $\left.\mathrm{MeSO}_{4}\right]$, was particularly efficient with all kinds of triglycerides [5]. It is noteworthy that $[\mathrm{bmim}]\left[\mathrm{PF}_{6}\right]$ and $[\mathrm{bmim}]\left[\mathrm{BF}_{4}\right]$ proved less efficient as a result of their immiscibility with the oils. The results of the study show that the ionic liquid coated enzymes do not automatically lead to better conversions, as was also observed in the production of $\alpha$-methylglucoside fatty acid esters [22] (Scheme 3). In the glycerolysis (Scheme 4) it is even the use of solvent quantities of [cpma] $\left[\mathrm{MsSO}_{4}\right]$ that works better than minimal coating quantities. Owing to its long alkyl chain $\left(-\mathrm{C}_{14} \mathrm{H}_{29}\right)$, [cpma] $\left[\mathrm{MeSO}_{4}\right]$ has an ideal affinity for fats and oils. In this case the optimized quantities depend on the task specificity of the ionic liquid in use. An optimized use of ionic liquids, with the concept of minimal use in mind, is

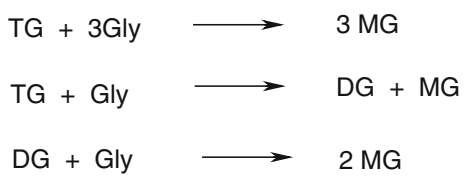

ionic liquid used:

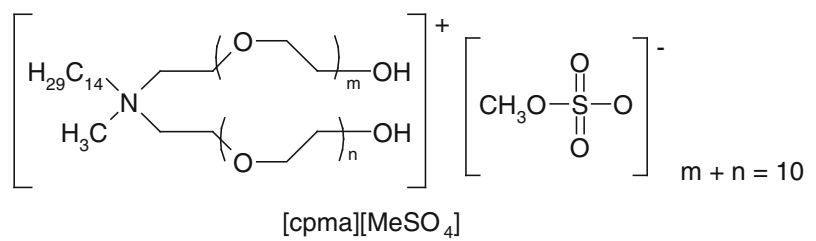

Scheme 4 Glycerolysis of vegetable and fish oil in amphiphilic cocosalkyl pentaethoxymethyl ammonium methoxysulfate, [cpma] $\left[\mathrm{MeSO}_{4}\right]$, used in optimized solvent quantities. $T G$ triglyceride, $D G$ diglyceride, $M G$ monoglyceride an approach that should be considered in any kind of transformation to enhance greenness.

\section{Compatibility of lipases with ionic liquids}

Many enzymes maintain their structure and function in a non-aqueous environment. This is particularly the case for lipases, which are rather robust and show beneficial compatibility with many organic solvents. Such suitability is limited in polar solvents that absorb residual water from the enzyme, causing denaturation as the tertiary protein structure alters.

Elevated polarity is a typical feature of ionic liquids and many negatively influence enzyme activity as residual water is absorbed. However, literature reports are divided and it was found that catalytic activity increased in more polar ionic liquids, whereas in other cases the activity dropped. This indicates that the enzyme-ionic liquid interaction is not following obvious rules. In addition, the substrate-ionic liquid interaction should be considered. A careful ionic liquid choice that is based on the screening of available liquids is therefore very important to find a combination that enhances transformation rates. A systematic way to approach the problem can be chosen when certain parameters are fixed. This is realized by using water-immiscible ionic liquids, which typically maintain enzyme activity. These ionic liquids comprise either waterrepellent cations such as $\mathrm{PR}_{4}{ }^{+}$and $\mathrm{NR}_{4}{ }^{+}(\mathrm{R}=$ long alkyl chains) or the anions $\mathrm{PF}_{6}^{-},\left(\mathrm{CF}_{3} \mathrm{SO}_{2}\right)_{2} \mathrm{~N}^{-}$and others. The research on enzyme-ionic liquid compatibility is also directed towards less polar ionic liquids. Another approach consists in the exploration of enzymes from extremophiles. These extremophiles have been known for quite some time but still represent an opportunity for discoveries. In relation to ionic liquids, halophiles found in salt lakes appear as interesting matches and need to be explored in particular.

Enzymes theoretically dissolve in ionic liquids and can become fully immobilized therein [17]. However, this is not a general property as some ionic liquids do not dissolve enzymes, or if soluble therein they denature. Experiments with Candida antarctica lipase B showed that ionic liquids such as $[\mathrm{emim}]\left[\mathrm{EtSO}_{4}\right],[\mathrm{bmim}][$ lactate $],\left[\mathrm{EtNH}_{3}\right]\left[\mathrm{NO}_{3}\right]$ and $[$ bmim $]\left[\mathrm{NO}_{2}\right]$ dissolved them but the reaction rate dropped significantly, whereas other ionic liquids, like [bmim] $\left[\mathrm{BF}_{4}\right]$ and $[\mathrm{bmim}]\left[\mathrm{PF}_{6}\right]$, did not dissolve this lipase and the activity remained high [13]. Thus, many enzymes can be immobilized in ionic liquid mixtures. From a process engineering point of view this property is of interest and merits being further explored as sustainable biphasic processing can be envisioned. The product isolation would be simplified as the solvent and the enzymes are separated easily. The underlying protein solubility is based on the 
fact that proteins contain charges found as salt bridges. The typical ions in the protein structures are carboxylate $\left(-\mathrm{COO}^{-}\right)$and ammonium ions $\left(-\mathrm{NH}_{3}{ }^{+}\right)$. In addition, certain ionic liquids like the imidazolium-based salts form hydrogen bonds with the carbonyl function in peptide bonds. The protein solubility is reduced in water-repellent ionic liquids that typically contain fluorinated anions like $\mathrm{PF}_{6}^{-}, \mathrm{CF}_{3} \mathrm{SO}_{2} \mathrm{~N}^{-}$and newer variants. It is proposed that here free enzymes are simply suspended during mixing, and vigorous shaking may compensate for incompatibility. The use of reduced amounts of ionic liquids that do not mix with lipases but maintain their function is possible with immobilized lipases like Novozyme 435 (Sect. "Reversible esterification with coated immobilized lipase") that can be coated with such ionic liquids. The ionic liquids are absorbed within the polymeric matrix and in this respect create a micro-environment where substrates can be dissolved and then delivered to the immobilized enzyme that is freely accessible as they hypothetically do not interact with the ionic liquid.

In general, the compatibility of enzymes with ionic liquids is a necessary quality; a further aspect are used quantities, which need to be reduced to an optimal but minimal amount.

\section{Comparison of solvent quantities to minimal use}

In chemical synthesis ionic liquids are used in solvent quantities [30] and comparable procedures are used for biotransformation [12, 23, 28, 31]. With the use of ionic liquid coated enzymes a minimal solvent approach is possible. In addition in biotransformation solvents are not needed as heat exchange modulators. The key issue in all biotransformations with ionic liquids is enzyme activity. But, the activity depends not only on compatibility with the ionic liquid in use; substrates also need to be available to the enzyme to become transformed and in this respect suitable ionic liquids have to be chosen too. The determination of solubility products for solutes in ionic liquids is not widely reported in the literature. Some values such as maximal water content are frequently found and were usually determined by Karl Fischer titration; glucose solubility information is also found for a range of ionic liquids. The large number of ionic liquids, more than a $1,000,000$ with all possible permutations, turns systematic data generation into a never-ending task. Moreover, many ionic liquids are expensive or need to be synthesized first. In addition purification procedures are often laborious. Other approaches use theoretical calculations that may help to identify valuable candidates.

The screening of reaction conditions with small sample quantities is a practicable approach for the evaluation of

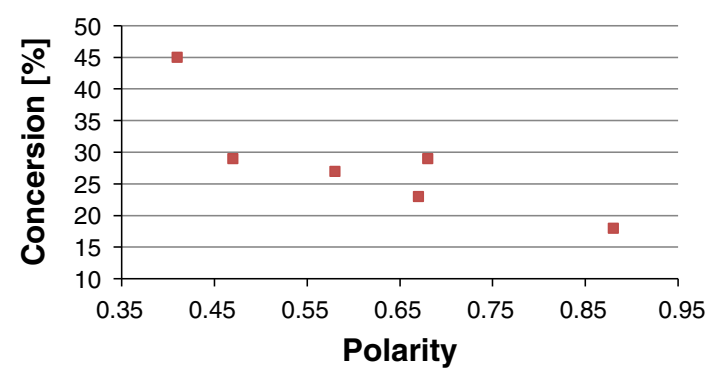

Fig. 4 Lipase-mediated biotransformation of myristic acid with $\alpha$-methylglucoside under solvent conditions. The trend shows lower conversions with increasing polarity: [thtdp] $\left[\mathrm{PF}_{6}\right]<$ [bdmim] $\left[\mathrm{PF}_{6}\right]<[\mathrm{hpyr}]\left[\mathrm{PF}_{6}\right]<[$ mpim $]\left[\mathrm{PF}_{6}\right]<[$ bmim $]\left[\mathrm{PF}_{6}\right]<[$ bmpyr $]\left[\mathrm{PF}_{6}\right]$ [22]

ionic liquids. In a screening some parameters can be fixed. For example, the esterification of $\alpha$-methylglucoside with fatty acid ionic liquids with the $\mathrm{PF}_{6}{ }^{-}$anion was screened in solvent quantities and with coated lipase. In solvent conditions only low conversions were possible, and with increasing polarity yields tended to be even lower (Fig. 4). The polarities of the substrate $\alpha$-methylglucoside and the fatty acids are obviously different and the product is an amphiphilic molecule. The radical reduction of the solvent quantity allowed a multiphase conversion with improved results (Fig. 6) (Sect. "Ionic liquid solvent safe/save strategy").

\section{Multiphase bioconversion with ionic liquids}

Multiphase bioconversions allow transformations with immiscible reaction partners (Fig. 5). Ionic liquid coated Novozyme 435 was examined in combination with organic solvents and solvent-free conditions [19]. Good conversions of citronellol with vinyl acetates of fatty acids were obtained (Scheme 2). The direct esterification with shortchain fatty acids and $\alpha$-methylglucoside is equally possible with this coated catalyst under solvent-free conditions. This process is actually a multiphase transformation and the mixture has typically a sludge-like appearance (Scheme 3, Fig. 3) [22]. In this transformation the condensing water was removed by molecular sieves. Short-chain fatty acids are liquids above $60^{\circ} \mathrm{C}$ and therefore no solvent is needed as the substrate is liquid. The solvent-free use of ionic liquid coated immobilized lipase improved yields significantly in comparison to the use with non-coated lipase under solvent-free conditions. The results were comparable to the use of acetone as solvent. The use of ionic liquids as coating represents a form of minimal ionic liquid use. That the transformation became much more efficient than with solvent quantities of the same ionic liquids (Fig. 6) is probably linked to the solubility of one of the reaction 
Fig. 5 Concept of bi- and multiphase processing with minimal and optimized ionic liquid quantities, respectively
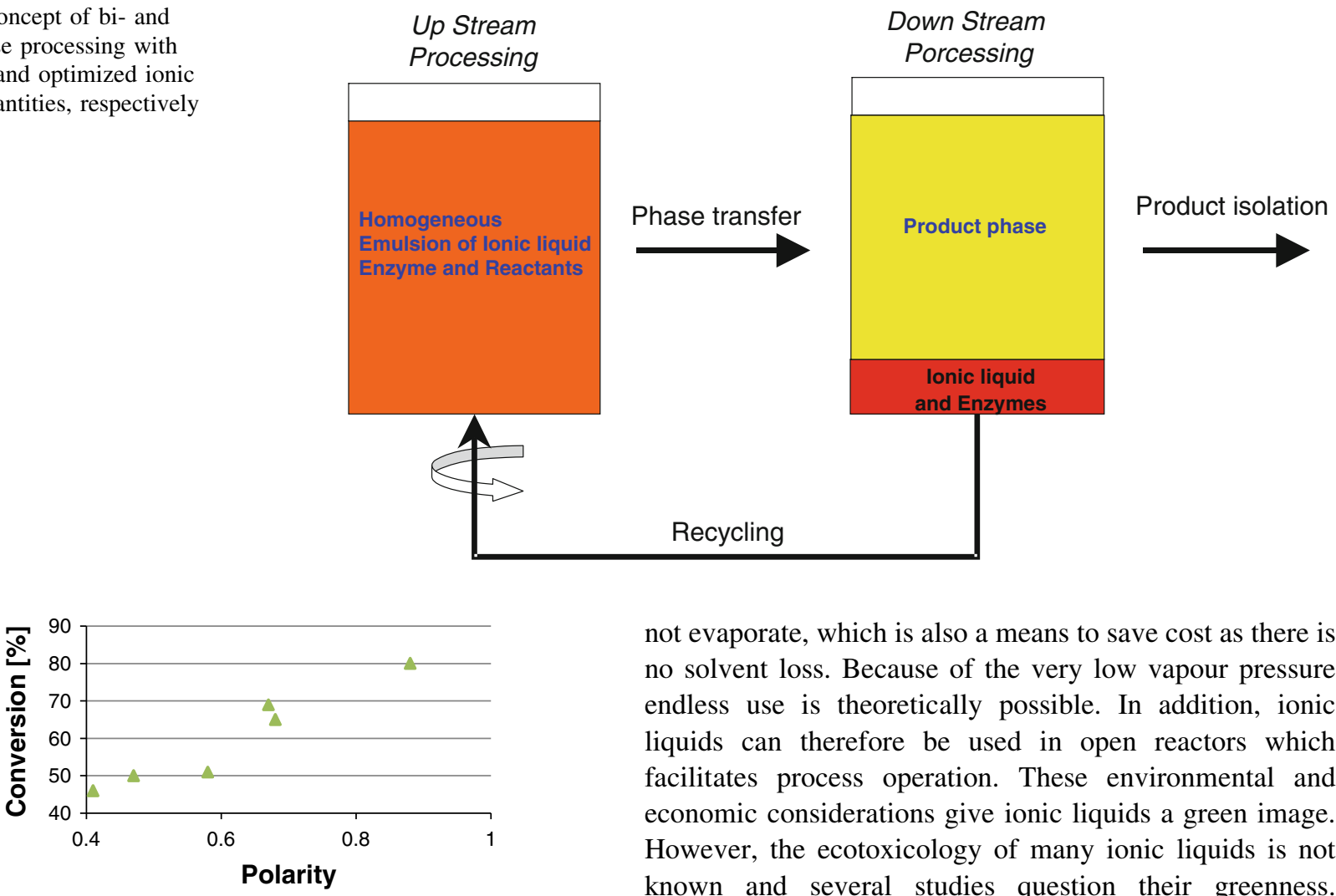

Fig. 6 Ionic liquid coated immobilized Candida antarctica lipase B in the conversion of myristic acid with $\alpha$-methylglucoside. The trend shows higher conversions with increasing polarity: [thtdp] $\left[\mathrm{PF}_{6}\right]$ $<$ bdmim $]\left[\mathrm{PF}_{6}\right]<[\mathrm{hpyr}]\left[\mathrm{PF}_{6}\right]<[$ mpim $]\left[\mathrm{PF}_{6}\right]<[$ bmim $]\left[\mathrm{PF}_{6}\right]<$ [bmpyr] $\left[\mathrm{PF}_{6}\right][22]$

partners, whereas the other partner tends to be excluded because of poor solubility. The exclusion of an incompatible reactant is less possible when small ionic liquid amounts are present. With an ionic liquid film on the carrier polymer surface a multiphase system is created and none of the reaction participants dominates the situation. It is important too that the $\alpha$-methylglucoside fatty acid esters are removed after formation from the catalyst carrier pores because the melting point of these products is above the processing temperature of $70^{\circ} \mathrm{C}$. It was observed that higher conversions were possible with increasing polarity of the ionic liquids in use (Fig. 6). Such a polarity effect was equally observed in a less pronounced way when ionic liquids were used as solvents with Pseudomonas cepacia lipase in a racemate resolution [23]. The multiphase bioconversions are also an approach for environmentally safe solvent use and to save solvents to reduce cost.

\section{Ionic liquid solvent safe/save strategy}

Ionic liquids are also considered for use in enzyme catalysis because they are safe for the environment as they do not evaporate, which is also a means to save cost as there is no solvent loss. Because of the very low vapour pressure endless use is theoretically possible. In addition, ionic liquids can therefore be used in open reactors which facilitates process operation. These environmental and economic considerations give ionic liquids a green image. However, the ecotoxicology of many ionic liquids is not known and several studies question their greenness. Recently, it was shown that the ionic liquid $\left[\mathrm{pmim}^{\mathrm{m}}\left[\mathrm{Tf}_{2} \mathrm{~N}\right]\right.$ is moderately toxic toward aquatic organisms [29]. The widely used anion hexafluorophosphate, $\mathrm{PF}_{6}{ }^{-}$, decomposes and releases HF, a very harmful acid [4]. This is not only a disadvantage in view of sustainability but also a drawback for emerging biphasic processing, where $\mathrm{PF}_{6}{ }^{-}$is chosen for its immiscibility properties with aqueous solutions. Alternative anions are therefore under development such as 1,1,2,2-tetrafluoroethansulfonate.

In conclusion, ionic liquids are green when used in containment to prevent losses to the environment. Nevertheless the green properties of ionic liquids are widely accepted and more research in bioprocess technologies is needed to exploit their beneficial properties.

To put this in a general perspective, the best way to save solvents is to omit them or apply minimal quantities to enable reactivity and selectivity. The use of small amounts of ionic liquids is therefore a logical consequence to enhance greenness. The use of ionic liquid coated enzymes is a concept to use reduced quantities of ionic liquids. It was shown that an ionic liquid film is often sufficient to accomplish biotransformations. These films are not covalently bound. To improve the concept of ionic liquid coated enzymes such films would need to remain in place which has not been achieved yet.

In summary, the current solvent-saving strategies are based on green solvents representing first-generation ionic liquids. They are already benign fluids and provide a viable 
option to reduce ecological impact and to replace conventional organic solvents. In the future second-generation ionic liquids will be available, which are specifically designed as task-specific solvents that are safe to the environment. The relative facility of the synthesis of ionic liquids is an opportunity to further optimize enzyme catalysis in this direction and use the technology for industrial biotransformations.

\section{Ionic liquids in industrial biotransformations}

A literature search for large-scale industrial applications with ionic liquids in biocatalysis yields no example [11, 15]. As there are so many ionic liquids available or that could be synthesized, it is imaginable to find the most suited ionic liquid for a specific application. There are obviously major obstacles to overcome for the use of ionic liquids as solvents. Although they promise to be beneficial in terms of greenness and cost efficiency, their application is not established. There are some evident problems in the use of ionic liquids: (1) They may contain impurities or become impure during processing. Such impurities, even in very small quantities, change for example the colour of the ionic liquid, but they are not easily detectable or simple to purify as distillation is impossible. (2) Ions can be exchanged with buffer solutions that are needed to control the $\mathrm{pH}$ to ensure enzymes function properly, or ion exchange may happen during work-up. Ion exchange is unwanted as the ionic liquids change their properties upon ion exchange [7].

In view of the vast virtual ionic liquid library $(>1,000,000$ variants) major research efforts are needed to enlarge current knowledge. All in all, there is no single versatile ionic liquid for all biotransformations; nevertheless, task-specific ionic liquids promise tailored solutions for clearly identified process needs. In this respect ionic liquids are an option for industrial bioconversions.

\section{Polarity determination of ionic liquids}

The polarity $\left(E_{T}^{N}\right)$ of ionic liquids is a key parameter in enzyme catalysis as activity may be closely related. This parameter was determined with a polarity-sensitive betaine dye known as Reichardt's dye (2,6-diphenyl-4-(2,4,6-triphenylpyridinio)phenolate) that provides distinguishable $\mathrm{UV}_{\max }$ absorptions [26, 27]. Because of a solvatochromic effect, the $\mathrm{UV}_{\max }$ absorption of the betaine shifts depending on the polarity of the ionic liquid.

The $\mathrm{UV}_{\max }$ of ionic liquids whose values were not found in the literature were recorded with this method that works
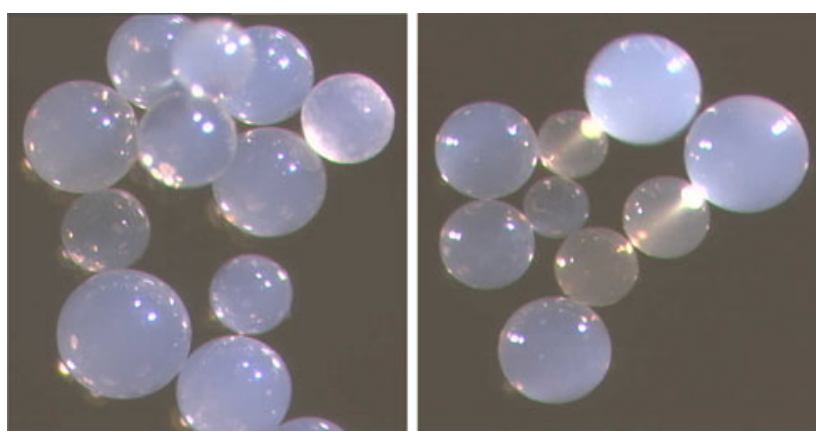

Fig. 7 Catalytic beads coated with $[\mathrm{bdmim}]\left[\mathrm{PF}_{6}\right]$ (left) and [hpyr] $\left[\mathrm{PF}_{6}\right]$ (right). Optical microscopy shows that the ionic liquids are fully adsorbed and the coated bead surfaces appear smooth. In addition the ionic liquids transform initially pale beads into transparent ones

well in general. A spatula tip of the betaine was added to a cuvette containing the ionic liquid and after homogenization the $\mathrm{UV}_{\max }$ was recorded. The dye concentration should be adjusted as a function of the intensity of the absorption. The method is possibly limited by the solubility of the betaine dye. Other dyes like the merocyanines are also described for accurate polarity determination [1] and the dye bishydrazine was studied for $[\mathrm{bmim}]\left[\mathrm{PF}_{6}\right]$ and $[\mathrm{bmim}]\left[\mathrm{BF}_{4}\right]$ [3]. A comparison of available solvatochromic methods for polarity determination is found in the comprehensive review by Poole [25] about ionic liquid properties. For the calculation of the polarity with the Reichardt's dye an $E_{T}$ is calculated initially with obtained $\lambda_{\max }$ (Eq. 1) and transformed (Eq. 2) into the more commonly used polarity value, $E_{T}^{N}=0 \ldots 1$, the polarity of water is the reference value set as $E_{T}^{N}=1$.

$E_{T}\left[\mathrm{kcal} \mathrm{mol}^{-1}\right]=h c v_{\max } N_{\mathrm{A}}=\frac{28591}{\lambda_{\max }}$

$E_{T}^{N}=\frac{E_{T(\text { ionic liquid })}-30.7}{32.4}$

where $h$ is Planck's constant, $c$ is the speed of light, $N_{\mathrm{A}}$ is Avogadro's number and $v_{\max }$ is the wavenumber.

\section{Ionic liquid coating of immobilized enzymes}

The coating of immobilized enzymes with ionic liquids is readily realized by the use of equal quantities of Novozyme 435 and ionic liquids $(\mathrm{w} / \mathrm{w})$ [22]. The ionic liquid was dissolved first in acetonitrile and then mixed with the catalyst beads containing immobilized Candida antarctica lipase B (Novozyme 435). A one-necked flask filled with this coating mixture was fixed to a Rotavapor and mixed 

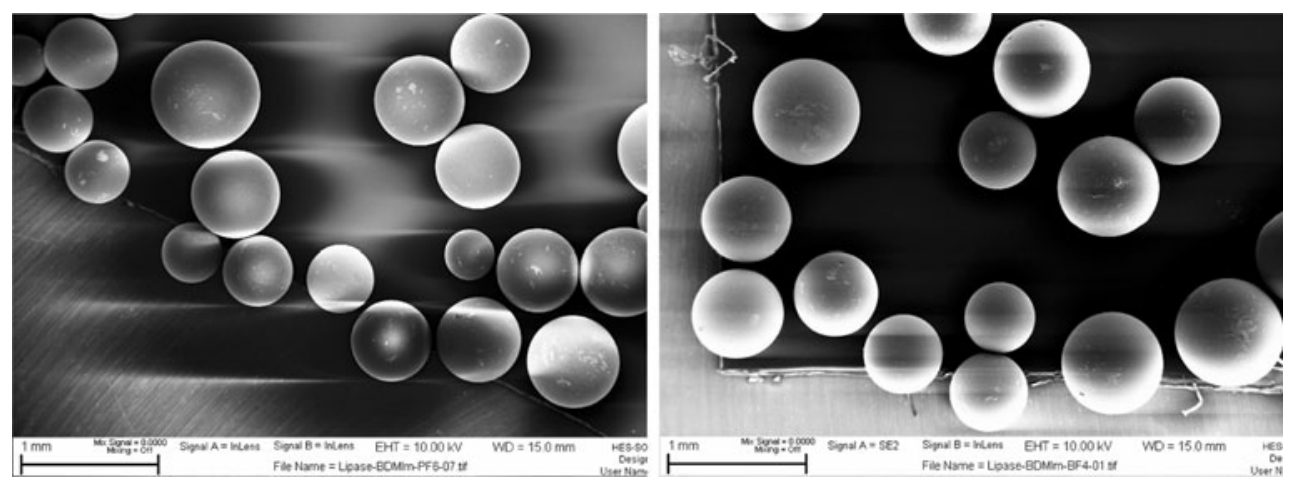

Fig. 8 Macro porous methylacrylate beads after coating with $[\mathrm{bdmim}]\left[\mathrm{PF}_{6}\right]$ and $[\mathrm{bdmim}]\left[\mathrm{BF}_{4}\right]$ scanned with a scanning electron microscope
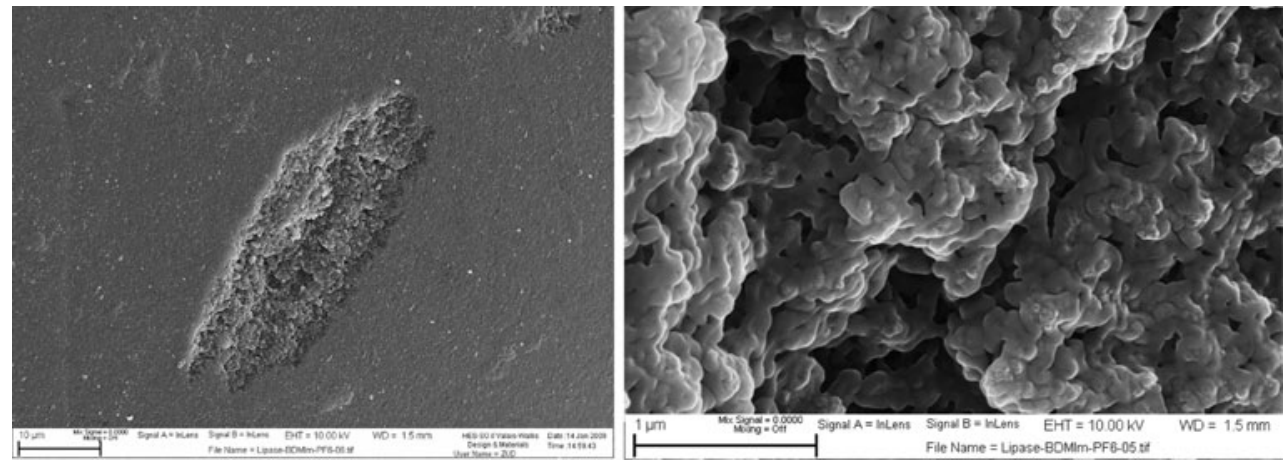

Fig. 9 Left A scar on an ionic liquid, [bdmim] $\left[\mathrm{PF}_{6}\right]$, coated bead, and the same area at higher magnification shows the interior of the coated bead (right)
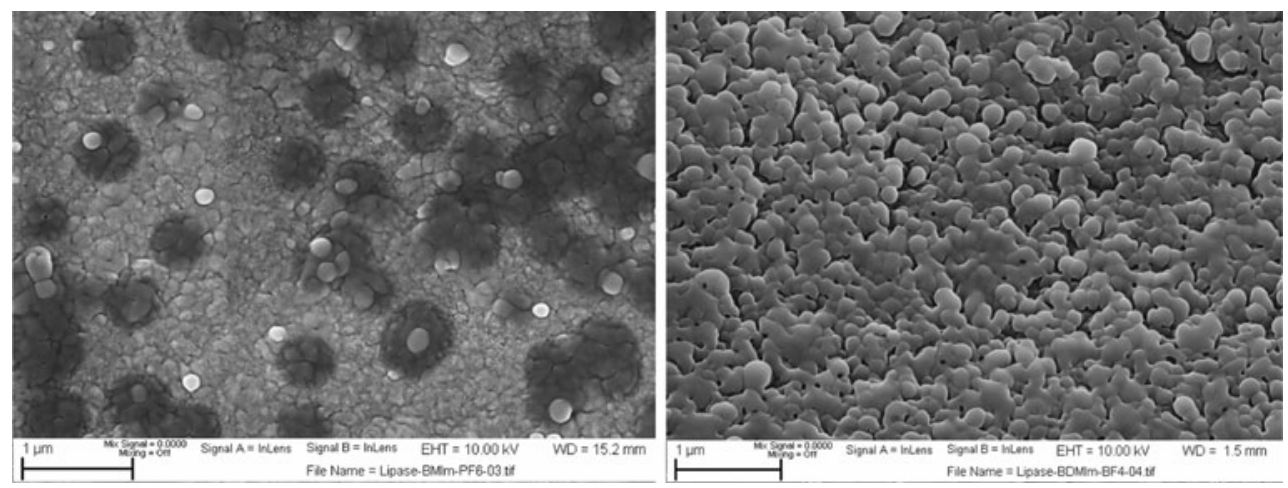

Fig. 10 Bead surface of the polymeric carrier coated with the room temperature ionic liquid [bmim] $\left[\mathrm{PF}_{6}\right]$ is spotted (left), whereas no spots are visible with $[\mathrm{bdmim}]\left[\mathrm{BF}_{4}\right]$ whose melting point is above room temperature (right)

Table 1 Elemental analysis of the spotted surface of the coated carriers with room temperature $[\mathrm{bmim}]\left[\mathrm{PF}_{6}\right]$

\begin{tabular}{llrll}
\hline Element & \multicolumn{4}{l}{ Proportion (\%) } \\
\cline { 2 - 5 } & $\mathrm{C}$ & $\mathrm{O}$ & $\mathrm{F}$ & $\mathrm{P}$ \\
\hline White zone & 63.7 & 12.9 & 19.1 & 4.4 \\
Dark spots & 67.5 & 9.8 & 18.0 & 4.8 \\
\hline
\end{tabular}

The normalized results show that the ionic liquid is evenly distributed all over the surface
(30 rpm) at room temperature for $20 \mathrm{~min}$. Then the acetonitrile was completely evaporated under reduced pressure at ambient temperature. The obtained coated beads were directly used, or stored in a desiccator overnight. This procedure has proven so far to be versatile and easy to handle. Various ionic liquids with cations ([ $\left.\mathrm{PR}_{4}\right],[\mathrm{bmim}]$, [pmim], [pyr], [hpyr]) combined to $\mathrm{PF}_{6}{ }^{-}$and $\mathrm{BF}_{4}{ }^{-}$anions were successfully prepared as microscopic analysis indicates. 

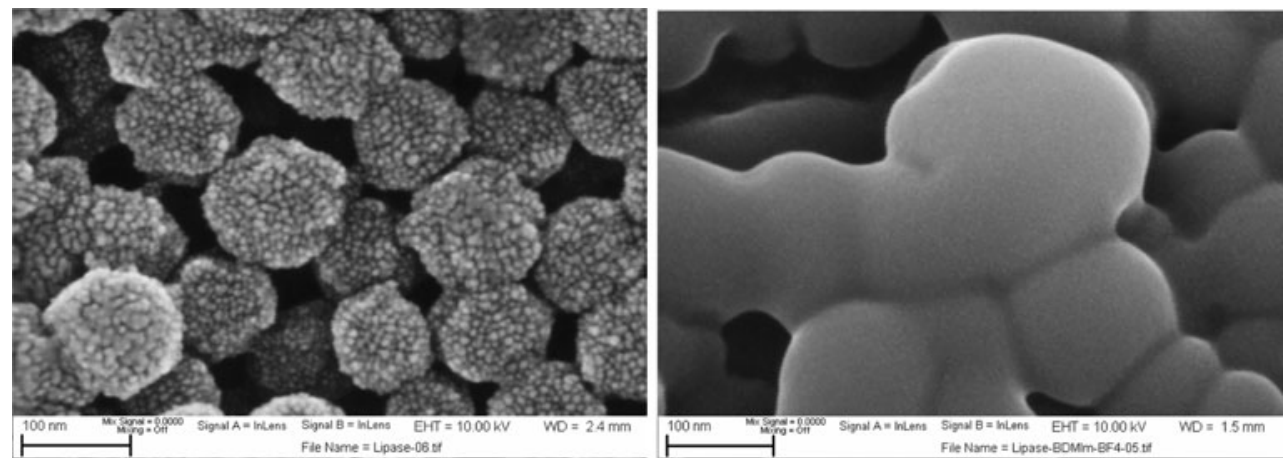

Fig. 11 Left Microporous structure of uncoated Novozyme 435. Right The same structure coated by [bdmim] $\left[\mathrm{BF}_{4}\right]$

Analysis of ionic liquid coating

Optical microscopy showed that coated beads become transparent (Fig. 7), and this optical particularity persisted after use of the beads in a 3-day-long catalysis experiment. In a first evaluation the analysis indicates that the ionic liquid is fully adsorbed as the surfaces of the beads are not covered. It is known that Novozyme 435 beads provide good sorption qualities which is also the case for ionic liquids [8]. To investigate the nature of the coating more closely scanning electron microscopy was employed.

\section{Coating analysis by electron microscopy}

Scanning electron microscopy (SEM) also indicates that ionic liquids such as $[\mathrm{bdmim}]\left[\mathrm{PF}_{6}\right]$ and $[\mathrm{bdmim}]\left[\mathrm{BF}_{4}\right]$ are fully adsorbed on the beads (Fig. 8), although approximately the same weight of ionic liquid and carriers were used. The macroscopic image obtained with the electron microscope provides more details, and some impurities or scars on the surface of the beads are visible (Fig. 9).

A magnification of the scar area on the bead surfaces allowed a closer analysis of the beads' interior. In the scar zone a fine microstructure was detected comprising canals reaching into the bead despite the coating (Fig. 9). The surface of the macroporous polymer was covered evenly all over by the ionic liquids (Fig. 10).

Before the SEM analysis the samples were covered with a metallic film to enhance imaging quality. In the analyses discussed here, gold plasma was used to cover the surfaces of the samples. The first analysis of an entire bead coated with $[\mathrm{bmim}]\left[\mathrm{PF}_{6}\right]$ showed a spotted surface (Fig. 10). These dark spots are found on a bright background, which represents the gold film surface. The dark spots are presumably areas where gold particles sank into the ionic liquid that is present as fluid film on the surface. Conversely, these spots were not observed when $[\mathrm{bdmim}]\left[\mathrm{BF}_{4}\right]$ (Fig. 10) was used. The relevant difference between these two ionic liquids is the melting point. Although [bmim] $\left[\mathrm{PF}_{6}\right]$ is a room temperature ionic liquid, the melting point of $[\mathrm{bdmim}]\left[\mathrm{BF}_{4}\right]$ is $37^{\circ} \mathrm{C}$ [16]. An elemental analysis of the bead coated with $[\mathrm{bmim}]\left[\mathrm{PF}_{6}\right]$ showed that this ionic liquid is evenly distributed all over the surface. The quantity of fluorine and phosphorus atoms is the same in white and spotted areas (Table 1).

Electron microscopy of crunched beads

The quality and nature of the coatings were examined more closely by first mechanically crunching the beads to allow SEM analysis of their inner structure. As reference, noncoated Novozyme 435 was equally examined and it showed a fine nanostructure (Fig. 11). The nanoparticles swell through the ionic liquid coating but the structure maintains porosity.

\section{Conclusions}

Ionic liquid coated enzymes allow the use of minimal quantities of ionic liquids, multiphase catalysis, and solubility of various substrates and enzymes. It is also a concept that saves solvents and renders biocatalysis green. The activation effect of ionic liquids on enzymes is based on their very particular properties. It is obvious from the literature that the application of ionic liquids is limited mostly to lipases, and other enzymes have been less examined thus far. That lipases are often employed is related to their ability to function under water-free conditions. The coating of enzymes-native or immobilizedwith ionic liquids is a form of minimal use of ionic liquids, permitting one to work under solvent-free conditions. Ionic liquids can also be used in optimized quantities for transformations where the amount of liquid is typically somewhat above minimal solvent conditions. In other cases a supplemental solvent is employed such as $\mathrm{scCO}_{2}$, hexane, acetone and others. Beneficial multiple solvent effects are expected, as are already known for organic solvent 
mixtures [26]. The multi-solvent mixtures comprising organic solvents can be the superior choice to pure ionic liquids but are not necessarily green. There are millions of ionic liquids imaginable, outnumbering the number of organic solvents (300-600) by far, and they provide an opportunity to develop minimal solvent biocatalyses.

Acknowledgments The work on ionic liquid coated lipases was possible through the support by RealTech, Project No: 18644.

\section{References}

1. Buncel E, Rajagopal S (1990) Sovatochronism and solvent polarity scales. Acc Chem Res 23:226-231

2. Dominguez de Maria P (2008) "Nonsolvent" applications of ionic liquids in biotransformations and organocatalysis. Angew Chem Int Ed 47:2-10

3. Ferrer B, Garcia H, Schultz KP, Nelsen SF (2007) Mixed valence compounds as probes to determine the polarity of 1-butyl-3methylimidazolium ionic liquids. J Phys Chem B 111:13967-13970

4. Gathergood N, Garcia MT, Scammells PJ (2004) Biodegradable ionic liquids: part I. Concept, preliminary targets and evaluation. Green Chem 6:166-175

5. Guo Z, Xu X (2005) New opportunity for enzymatic modification of fats and oils with industrial potentials. Org Biomol Chem 3:2615-2619

6. Habulin M, Sabeder S, Paljevac M, Knez Z (2007) Lipase-catalyzed esterification of citronellol with lauric acid in supercritical carbon dioxide/co-solvent media. J Supercrit Fluids 43:199-203

7. Han X, Armstrong DW (2007) Ionic liquids in separations. Acc Chem Res 40:1079-1086

8. Heinsman NWJT, Schroën CGPH, Van Der Padt A, Franssen MCR, Boom FM, van't Riet K (2003) Substrate sorption into the polymer matrix of Novozyme 435 and its effect on the enantiomeric ratio determination. Tetrahedron Asymmetry 14:2699-2704

9. Itoh T, Han S, Matsushita Y, Hayase S (2004) Enhanced enantioselectivity and remarkable acceleration on the lipase-catalyzed transesterification using novel ionic liquids. Green Chem 6:437-439

10. Itoh T, Matsushita $\mathrm{Y}$, Abe $\mathrm{Y}$, Han S, Wada S, Hayase S, Kawatsura M, Takai S, Morimoto M, Hirose Y (2006) Increased enantioselectivity and remarkable acceleration of lipase-catalyzed transesterification by using an imidazolium PEG-alkyl sulfate ionic liquid. Chem Eur J 12:9228-9237

11. Kim M-J, Lee JK (2004) Enzymes coated with ionic liquids. US 2004/0087462 A1

12. Kragl U, Eckstein M, Kaftzik N (2002) Enzyme catalysis in ionic liquids. Curr Opin Biotechnol 13:565-571

13. Lau RM, Sorgdrager MJ, Carrea G, van Rantwijk F, Secundo F, Sheldon RA (2004) Dissolution of Candida antarctica lipase B in ionic liquids: effects on structure and activity. Green Chem 6:483-487
14. Lee JK, Kim M-J (2002) Ionic liquid-coated enzyme for biocatalysis in organic solvent. J Org Chem 67:6845-6847

15. Liese A, Seelbach K, Wandrey C (2006) Industrial biotransformations. Wiley- $\mathrm{VCH}$, Weinheim

16. López-Martin I, Burello E, Davey PN, Seddon KR, Rothenberg G (2007) Anion and cation effects on imidazolium salt melting points: a descriptor modelling study. Chem Phys Chem 8:690695

17. Lozano P, de Diego T, Iborra JL (2006) Immobilization of enzymes for use in ionic liquids. In: Guisan JM (ed) Immobilisation of enzymes and cells, 2nd edn. Methods in biotechnology, vol 22. Humana, Totowa, pp 257-268

18. Lozano P, De Diego T, Carrié D, Vaultier M, Iborra JL (2001) Over-stabilization of Candida antarctica lipase B by ionic liquids in ester synthesis. Biotechnol Lett 23:1529-1533

19. Lozano P, Piamtongkam R, Kohns K, De Diego T, Vaultier M, Iborra JL (2007) Ionic liquids improve citronellol ester synthesis catalyzed by immobilized Candida antarctica lipase B in solventfree media. Green Chem 9:780-784

20. Lozano P (2010) Enzymes in neoteric solvents: from one-phase to multiphase systems. Green Chem 12:555-569

21. Moniruzzaman M, Kamiya N, Goto M (2010) Activation and stabilization of enzymes in ionic liquids. Org Biomol Chem 8:2887-2899

22. Mutschler J, Rausis T, Bourgeois J-M, Bastian C, Zufferey D, Mohrenz IV, Fischer F (2009) Ionic liquid-coated immobilized lipase for the synthesis of methylglucose fatty acid esters. Green Chem 11:1793-1800

23. Park S, Kazlauskas RJ (2003) Biocatalysis in ionic liquidsadvantages beyond green technology. Curr Opin Biotechnol 14:432-437

24. Park S, Kazlauskas RJ (2001) Improved preparation and use of room temperature ionic liquids in lipase-catalyzed enantio- and regioselective acylations. J Org Chem 66:8395-8401

25. Poole FC (2004) Chromatographic and spectroscopic methods for the determination of solvent properties of room temperature ionic liquids. J Chromatogr A 1037:49-82

26. Reichardt C (2007) Solvents and solvent effects: an introduction. Org Process Res Dev 11:105-113

27. Reichardt C (2005) Polarity on ionic liquids determined empirically by means of solvatochromic pyridinium $\mathrm{N}$-phenolate betaine dyes. Green Chem 7:339-351

28. Van Rantwijk F, Sheldon RA (2007) Biocatalysis in ionic liquids. Chem Rev 107:2757-2785

29. Ventura SPM, Gonçalves AMM, Gonçalves F, Coutinho JAP (2010) Assessing the toxicity on $\left[\mathrm{C}_{3} \mathrm{mim}\right]\left[\mathrm{Tf}_{2} \mathrm{~N}\right]$ to aquatic organisms of different trophic levels. Aquat Toxicol 96:290-297

30. Wasserscheid P, Welton T (2002) Ionic liquids in synthesis. Wiley-VCH, Weinheim

31. Yang Z, Pan W (2005) Ionic liquids: green solvents for nonaqueous biocatalysis. Enzyme Microb Technol 37:19-28

32. Zhao H (2005) Effect of ions and other compatible solutes on enzyme activity, and its implication for biocatalysis using ionic liquids. J Mol Catal B Enzym 37:16-25

33. Zhao H (2010) Methods for stabilizing and activating enzymes in ionic liquids-a review. J Chem Technol Biotechnol 85:891-907 